MANAGEMENT AND MARKETING

\title{
FINANCING AND EFFECTIVENESS OF GEORGIAN HEALTHCARE SYSTEM
}

Davit Meparishvili, Doctor of Business administration, Invited Professor, Ilia State University, Tbilisi, Georgia, ORCID ID: https://orcid.org/0000-0001-7454-2521

Manana Maridashvili, Doctor of Business administration, Professor, Georgian National University, Tbilisi, Georgia, ORCID ID: https://orcid.org/0000-0002-2798-9643

Ekaterine Sanikidze, Doctoral student of Business administration, Georgian Technical University. Tbilisi, Georgia, ORCID ID: https://orcid.org/0000-0003-0466-1845

\section{DOI: https://doi.org/10.31435/rsglobal_conf/30082021/7650}

\begin{abstract}
Assessing the effectiveness of the Georgian healthcare system in the modern period and conditions, takes into account the results achieved, as well as the main problems that hinder the effective functioning of this important field; At the same time, it is important to develop the main directions of their solution, where we consider the improvement of the state policy-making process during the implementation of reforms in the healthcare sector, which should take into account the state of health of the population, quality of healthcare services, results, health care; furthermore disease prevention, equality, financial provision, access to health care, efficiency, rational allocation of health care system resources and other key features of the health care system.
\end{abstract}

Keywords: Financing, effectiveness, universal health care, health care system, health care costs, profit-oriented hospitals.

Introduction. According to the study materials, life expectancy in Georgia has increased over the last 25 years, child and maternal mortality has decreased, public spending on health care has increased 21 times, and in the last 3 years it has almost doubled, which obviously has a positive impact on public health and the country's economy. On growth. However, the share of state funding in health expenditures still lags significantly behind not only the threshold set by the World Health Organization, but also that of many low-income countries. Referrals to a family doctor are also low, which indicates problems in the development of the primary health care system. In this regard, it is advisable to promote the development of the primary health care system, and in relation to public health expenditures, increase it in accordance with the recommendations of the World Health Organization [1].

It is true that according to statistics, the number of clinics increased from 2011 to 2021, however, the excess medical infrastructure was often created without taking into account the medical needs of the population, and it should be noted that the rapid increase in the number of clinics was the result of a poorly planned universal health program.

It should be noted that the share of private, profit-oriented hospitals in Georgia in the total number of hospitals is $86 \%$ and is quite high compared to many developing and developed countries, the remaining 14\% (mainly specialized medical institutions such as psychiatric, drug, etc.) are stateowned. Owned. We consider it important to promote the development of other forms of ownership, in particular non-profit (non-profit) and public-private partnership medical organizations, which play an important role in developed countries and thus increase competition between forms of ownership of medical organizations, promote access to health care. Raising and bringing the Georgian healthcare system closer to the existing experience of the countries of the world. [2]

The number of hospital beds exceeds the needs of the population. In 2021 only $49 \%$ of the beds were loaded, which is significantly lower than the EU (77\%) and CIS (83\%) averages. All this indicates the inefficient use of invested capital and other resources. Small and possibly low-efficiency facilities were mainly introduced to the market, which did not have a significant impact on the market share of the leading facilities, although it did reduce the effective utilization rate of the installed capacity [3].

It should be noted that funding for health programs is growing every year and in 2021 will exceed one billion GEL. Its largest share, more than $70 \%$, is universal health program spending. It is true that after the launch of the universal healthcare program in Georgia, the share of out-of-pocket payments in total healthcare expenditures decreased, but in 2021 , about $56 \%$ of healthcare expenditures were still paid out of pocket, which is still high compared to EU (16\%) and regional 
(38\%). It should be noted that according to the Health Policy Development Document, the Government of Georgia will reduce the share of out-of-pocket payments to $30 \%$ by 2030 , and achieve more than $5 \%$ of the share of public spending on GDP, according to the DRG (Diagnosis-Related Groups). Similar diseases (e.g., diseases of the cardiovascular system) united in one nosological group) plan to increase the share of inpatient cases reimbursed by $100 \%$ and the share of primary health care and prevention expenditures by $40 \%$ in total costs. [4].

It is noteworthy that despite the significant increase in health expenditures in recent years, according to available data, among European and regional countries, Georgia is still one of the last places in the share of public health expenditures in both total health expenditures $(2017-38 \%)$ and GDP (2017 - 2.9\%) and in the state budget (2017 - 10\%). [5]

Despite a number of health care reforms in terms of financial stability and risk assessment, it is important to note that there is excess production capacity in the sector and it is not being used effectively. According to 20120 statistics, the bed load rate in Georgia is $49 \%$, which is significantly lower than the EU (77\%) and CIS (83\%) average rates. One of the reasons for the low efficiencies is the fragmentation of the sector. $60 \%$ of facilities account for only $10.9 \%$ of hospitalizations, while the average size of hospitals is 3 times lower than the OECD rate per bed. Clearly, all this has a negative impact on the financial performance of the sector. It is important to improve the cost-effectiveness of health services and to introduce the DRG (Diagnostic Grouping) model of financing hospitals and emergency services, enacting new standards for hospital infrastructure and human resources, which will significantly reduce the fragmentation of the sector [6].

Despite significant improvements in access, demand for primary health care in Georgia is still low, with an outpatient referral rate of 3.6 per capita in 2019, well behind the EU (7.0).

At the same time, there is an abundance of doctors and a shortage of nurses in Georgia. There are only 0.6 nurses per doctor in Georgia, and from 2 to 5 nurses in European countries. As a result, Georgian doctors are 3-5 times less productive than their counterparts in European countries, which means that they serve fewer patients. [7]

The state seeks to manage health care costs through uniform tariffs (Resolution 520 and other), which must be methodologically sound, quality-oriented and periodically adjusted, otherwise their negligence will jeopardize the sector's financial stability, quality of service and patients' financial security.

Conclusions. The efficient and optimal functioning of the Georgian healthcare system envisages the improvement of such important issues as: improvement of the legal framework, improvement of the quality of medical services, availability of quality and safety assurance mechanisms in terms of infrastructure and human resources (permits, licenses, state systems). Optimization of staff, accreditation and increase of remuneration, rational use of state investments, introduction and dissemination of innovative and high-tech products / services, projects, precise definition of the volume of medical services fully funded by the state and balanced by real programmatic opportunities. Ensuring effective communication with the public using all modern media and optimal coverage of other current areas, which will have a positive impact on the health system of the country, the improvement of the health status of the population and raising the standard of living.

\section{REFERENCES}

1. Barasa, E. W., Molyneux, S., English, M., \& Cleary, S. (2015). Setting healthcare priorities at the macro and meso levels: A framework for evaluation. International Journal of Health Policy and Management, 4(11), 719-732.

2. Chee, G., Pielemeier, N., Lion, A., \& Connor, C. (2013). Why differentiating between health system support and health system strengthening is needed. The International Journal of Health Planning and Management, 28(1), 85-94.

3. Daniels, N., \& Sabin, J. (1997). Limits to health care: Fair procedures, democratic deliberation, and the legitimacy problem for insurers. Philosophy \& Public Affairs, 26(4), 303-350.

4. Glassman, A., Chalkidou, K., Giedion, U., Teerawattananon, Y., Tunis, S., Bump, J. ～B., ～\& PichonRiviere, A. (2012). Priority-Setting Institutions in Health. Global Heart, 7(1), 13-34.

5. Jamison, D. T., Alwan, A., Mock, C. N., Nugent, R., Watkins, D..2018). Universal health coverage and intersectoral action for health: Key messages from Disease Control Priorities, 3rd edition. Lancet (London, England), 391(10125), 1108-1120

6. Kapiriri, L., Lee, N.-M., Wallace, L. J., \& Kwesiga, B. (2019). Beyond cost-effectiveness, morbidity and mortality: A comprehensive evaluation of priority setting for HIV programming in Uganda. BMC Public Health, 19(1), 359.

7. Li, R., Hernandez-Villafuerte, K., Towse, A., Vlad, I., \& Chalkidou, K. (2016). Mapping priority setting in health in 17 countries across Asia, Latin America, and sub-Saharan Africa. Health Systems \& Reform, 2(1), 71-83. 